Session 3232

\title{
Engineering Criteria 2000 Challenges for Large Programs
}

\author{
Joseph L. A. Hughes and William E. Sayle \\ School of Electrical and Computer Engineering \\ Georgia Institute of Technology
}

In 1997 Georgia Institute of Technology, with ten undergraduate programs and one graduate program accredited by EAC/ABET, participated as one of five pilot evaluations under Engineering Criteria 2000. Each of the institutions selected for pilot visits has unique attributes which must be addressed within the context of the new criteria. Georgia Tech is a publiclysupported, highly-ranked research university, with over 5000 undergraduates and 2000 graduate students in the College of Engineering.

The School of Electrical and Computer Engineering (ECE) is the largest unit within the College of Engineering, with approximately 1,600 students in two accredited undergraduate programs, electrical engineering and computer engineering, plus approximately 700 graduate students. Approximately $50 \%$ of the undergraduates participate in the co-operative education program. The 85 faculty members span 10 major technical fields within electrical and computer engineering. Students may select from over 60 senior electives and the EE program allows students to satisfy their major design experience in any of 13 different areas of specialization, many of which include multiple course options. Large, flexible degree programs such as these face several challenges in satisfying Engineering Criteria 2000, particularly in demonstrating that all graduates achieve the specific outcomes required by the general and program criteria.

This paper provides a summary of our preparations for the 1997 pilot visit, focusing on the development of program objectives and outcomes and the implementation of assessment efforts. Based on our experiences, several "lessons learned" and unresolved issues are identified, with an emphasis on the challenges for large programs and universities.

\section{Engineering Criteria 2000}

Engineering Criteria 2000 (EC2000) incorporates several major changes in the accreditation model, as compared to the current Engineering Topics Criteria. Philosophically, EC2000 is based on three key principles:

- individual institutions and programs should define their mission and objectives based on the needs of their specific constituencies,

- programs should be evaluated against specific outcomes, derived from the program's objectives, which demonstrate that students are prepared for professional practice, and

- programs must have a functioning process for defining objectives and outcomes, assessing results, and using the data for continuous improvement of the program and process.

Much of the attention associated with the introduction of EC2000 has focused on the use of outcomes assessment for demonstrating program success. This change primarily affects the 
curriculum-related aspect of EC2000, replacing the lists of specific topics which had to be covered under earlier criteria. While completion of course requirements is likely to be the dominant method for ensuring that students achieve the expected outcomes, other elements also may be used. Other aspects of EC2000 related to students, faculty, facilities, institutional support, and financial resources are similar to earlier criteria, although it must be shown that these resources are appropriate to the program's objectives.

Although the specific EC2000 requirements are new, most programs and institutions are already engaged in some assessment activities. For example, student evaluation forms are commonly used for assessing professors and courses against a defined set of objectives or outcomes. By contrast, relatively few programs have in a place a systematic process for defining objectives and outcomes, conducting on-going assessment, and using the data for program improvement.

One model for a systematic process in shown in Figure 1. The smaller loop on the left side illustrates the process for determining objectives based on input from both internal and external constituencies, as well as for refining those objectives based on the assessment results. The larger loop on the right side illustrates the process for defining outcomes, methods, and assessment measures and for, then, implementing them and refining them. These activities generally occur within the context of the educational program and involve primarily faculty and students. Other models are possible, although they presumably would include similar elements.

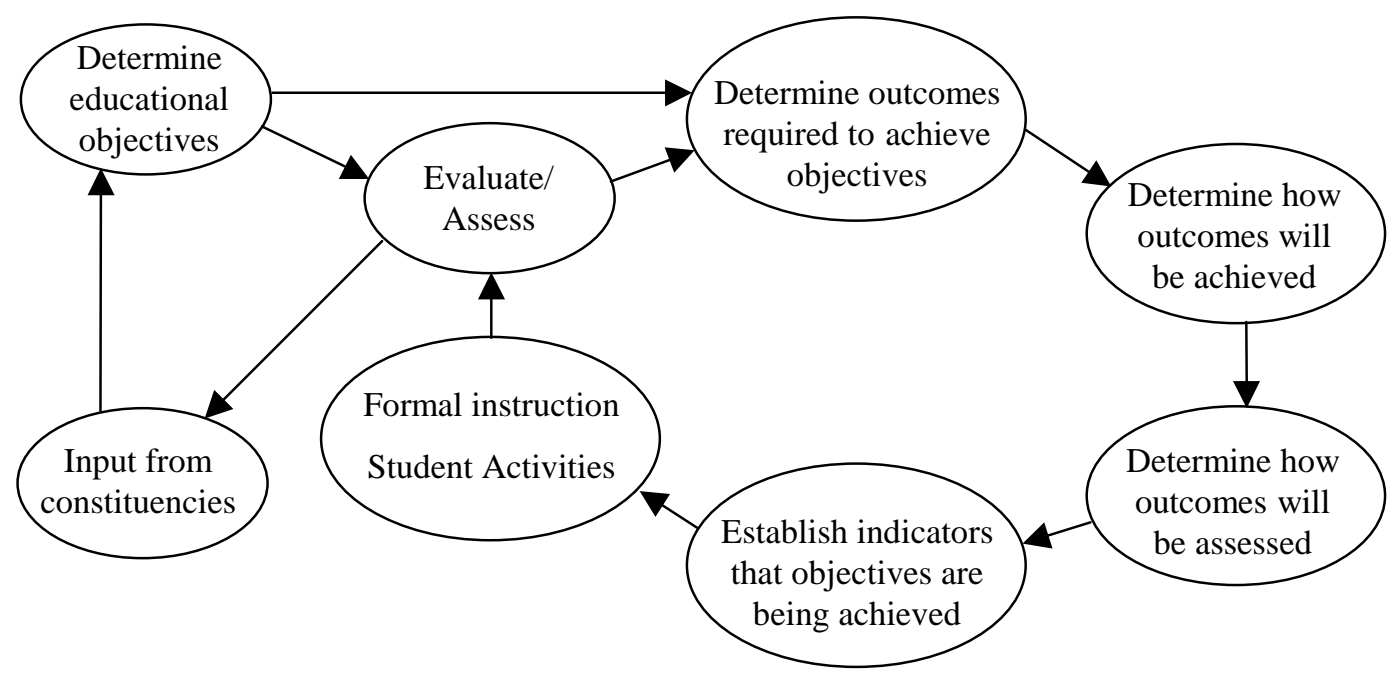

Figure 1. A model process for the systematic development of objectives and outcomes, program assessment, and continuous improvement. (Adapted from EAC Engineering Criteria 2000 program evaluator training materials. $\left.{ }^{1}\right)$

This process is intended to be on-going, with the ABET accreditation visits essentially serving to periodically sample and validate the results and process. Assessment activities should occur regularly between ABET visits, with faculty and other constituents periodically reviewing the data and refining objectives, outcomes, methods, assessment tools, etc. This process should occur at both the program level and at the level of individual faculty and courses. By contrast, the current accreditation process often produces a brief flurry of activity a few months before the 
visit, primarily by a small number of faculty members, with little activity between the completion of one visit and the start of preparations for the next visit.

\section{Defining Program Objectives and Outcomes}

Within ECE the process for defining the program objectives and outcomes for use under EC2000 began more than a year prior to the visit. This effort began with mission statements, goals, and related documents developed earlier as part of the College and Institute strategic planning and assessment effort. Comments and suggestions were solicited from faculty and members of the School's Industrial Advisory Board and an initial draft was developed by the authors and reviewed by the School Chair and selected faculty. The revised draft was distributed to all faculty for further comments. Separate Program Assessment Guides were developed for the electrical engineering and computer engineering programs, although much of the material is identical.

The final version of these guides included with our self-study identified nine educational objectives for the electrical engineering program, including the following examples:

- Students will obtain an ability to identify, formulate, and solve novel electrical engineering problems. This includes the planning, specification, design, implementation, and operation of systems, components, and/or processes that meet performance, cost, time, safety, and quality requirements.

- Students will obtain an ability to function and communicate effectively, both individually and within multidisciplinary teams.

- Students will experience an academic environment that facilitates and encourages learning and retention.

- The School will encourage cultural diversity within the ranks of the profession by being a leader in the education of minority and women students.

Based on these objectives, 23 outcomes were defined. Outcomes 1 - 14 are specifically required by Criterion 3 of EC2000 ${ }^{2}$ and the EE/CmpE program criteria ${ }^{2}$. Outcomes $15-23$ allow the School to monitor and improve its operations and programs, consistent with the educational objectives. Among the outcomes are the following examples:

2) All graduates are expected to have knowledge of core electrical and computer engineering topics and depth in at least two subdisciplines of electrical engineering (program criteria).

3) All graduates are expected to have an ability to use modern engineering techniques, skills, and tools, including computer-based tools for analysis and design (Engineering Criterion $3(\mathrm{k}))$.

9) All graduates are expected to have an ability to function on multi-disciplinary teams (Engineering Criterion 3(d)).

11) All graduates are expected to have an ability to convey technical material through oral presentation and interaction with an audience (Engineering Criterion 3(g)). 
15) The School's advising program meets the needs of the students for information regarding academic issues, career options, and graduate education.

17) The School provides appropriate support for underrepresented population groups, including ethnic and racial minorities, women, and disabled students.

22) Faculty members are active in research, consulting, and/or other professional activities, both to advance their own professional competence and to integrate new knowledge into the School's educational programs.

For each outcome, both the methods used to achieve it and the relevant assessment measures were identified. This process is summarized Tables 1-3, which are excerpted from the EE Program Assessment Guide and include the example objectives and outcomes listed previously. Table 1 identifies the relationships between educational objectives and outcomes, rating them as either strong or weak. Table 2 identifies the elements used to achieve the outcomes, including both curricular components and other activities such as co-op experience and support operations. Finally, Table 3 identifies which assessment measures are strong or weak measures of the achievement of each outcome.

Table 1. Relationships Between Educational Objectives and Outcomes

\begin{tabular}{|l|c|c|c|c|c|c|c|}
\hline \multirow{2}{*}{\multicolumn{1}{c|}{ Educational Objectives }} & \multicolumn{7}{c|}{ EE Program Outcomes } \\
\cline { 2 - 10 } & $\mathbf{2}$ & $\mathbf{3}$ & $\mathbf{9}$ & $\mathbf{1 1}$ & $\mathbf{1 5}$ & $\mathbf{1 7}$ & $\mathbf{2 2}$ \\
\hline Novel designs to meet requirements & $\mathrm{S}$ & $\mathrm{S}$ & $\mathrm{W}$ & $\mathrm{W}$ & & & $\mathrm{W}$ \\
\hline Communications & & & $\mathrm{S}$ & $\mathrm{S}$ & & $\mathrm{W}$ & \\
\hline Academic environment & & & $\mathrm{S}$ & & $\mathrm{S}$ & $\mathrm{S}$ & $\mathrm{W}$ \\
\hline Cultural diversity & & & $\mathrm{W}$ & & $\mathrm{S}$ & $\mathrm{S}$ & \\
\hline
\end{tabular}


Table 2. Elements Used to Achieve Program Outcomes

\begin{tabular}{|l|c|c|c|c|c|c|c|c|c|}
\hline \multirow{2}{*}{\multicolumn{1}{|c|}{ Resources and Strategies }} & \multicolumn{7}{|c|}{ EE Program Outcomes } \\
\cline { 2 - 10 } & $\mathbf{2}$ & $\mathbf{3}$ & $\mathbf{9}$ & $\mathbf{1 1}$ & $\mathbf{1 5}$ & $\mathbf{1 7}$ & $\mathbf{2 2}$ \\
\hline Curriculum Requirements & $\mathrm{X}$ & $\mathrm{X}$ & & & & & \\
\hline \multicolumn{1}{|c|}{ Required ECE Core } & & $\mathrm{X}$ & $\mathrm{X}$ & $\mathrm{X}$ & & & \\
\hline \multicolumn{1}{|c|}{ Major Design Experience } & & & & $\mathrm{X}$ & & & \\
\hline \multicolumn{1}{|c|}{ Technical Writing \& Public Speaking } & & & $\mathrm{X}$ & & & & \\
\hline \multicolumn{1}{|c|}{ Ethics Course } & $\mathrm{X}$ & $\mathrm{X}$ & $\mathrm{X}$ & $\mathrm{X}$ & & & \\
\hline Co-op and Internships & $\mathrm{X}$ & & & & $\mathrm{X}$ & $\mathrm{X}$ & \\
\hline Academic Advising Office & & & & & $\mathrm{X}$ & $\mathrm{X}$ & \\
\hline $\begin{array}{l}\text { GT Student Orientation and Retention } \\
\text { Programs }\end{array}$ & & & & & & $\mathrm{X}$ & $\mathrm{X}$ \\
\hline $\begin{array}{l}\text { Faculty and Staff Professional } \\
\text { Development Activities }\end{array}$ & & & & & & & \\
\hline
\end{tabular}

Table 3. Current Assessment Methods Used to Monitor Program Outcomes

\begin{tabular}{|c|c|c|c|c|c|c|c|}
\hline \multirow[b]{2}{*}{ Assessment Method } & \multicolumn{7}{|c|}{ EE Program Outcomes } \\
\hline & 2 & 3 & 9 & 11 & 15 & 17 & 22 \\
\hline Monitoring of student progress & $\mathrm{s}$ & $\mathrm{s}$ & & & $\mathrm{s}$ & W & \\
\hline CETL course evaluations & w & W & & & & $\mathrm{w}$ & \\
\hline Exit interviews/surveys & W & W & W & & $\mathrm{s}$ & S & W \\
\hline Employer surveys & & $\mathrm{s}$ & W & $\mathrm{s}$ & & W & \\
\hline ABET accreditation evaluations & $\mathrm{s}$ & $S$ & & & W & & W \\
\hline External advisory board feedback & w & $\mathrm{s}$ & & W & & w & \\
\hline Annual faculty performance reviews & & & & & & & $\mathrm{s}$ \\
\hline
\end{tabular}

The self-studies and Assessment Guides were distributed to all faculty members and members of the School's Industrial Advisory Board in early Fall 1997, a few weeks prior to the ABET visit. Based on feedback from these groups, discussions with our program evaluators, and the ABET report, these documents will be revised later this year. The primary changes will be a reduction in the number of educational objectives, particularly to consolidate those that correspond directly to outcomes; integration of the documents for the two programs into a single guide; and a reduction in the number of the assessment measures used for the EC2000 evaluation process. 


\section{Assessment Process}

Georgia Tech has been actively involved in assessment activities for more than five years. Initially these efforts focused on TQM (total quality management) and CQI (continuous quality improvement) processes, targeting both academic and support units, and included industry participation, particularly Milliken Corporation sponsorship of faculty and student programs and an IBM TQM grant. Later assessment efforts focused more on academic curricula, in part due to requirements imposed by the state Board of Regents. The College of Engineering played a leadership role in many Institute activities and had committees that developed and reviewed both general assessment processes and specific plans for Georgia Tech assessment activities.

In preparation for the ABET review, an alumni survey was mailed in Summer 1997 to all baccalaureate graduates in engineering from the classes of 1992 and 1993. These surveys included questions common to all majors and a set of major-specific questions developed by the individual Schools. Initial results of this survey were available at the time of the ABET review. Additionally, each program identified its own internal assessment processes.

Within ECE, the approach was to first collect all of the existing assessment data that we could locate from the past five years. This included survey results (regardless of who had conducted the survey), exit interview summaries, course evaluations, and other materials. Additionally, a list was developed of potential assessment measures, whether or not we actually had results available for that measure. All of these potential methods were then evaluated to determine whether or not they were useful in assessing the outcomes that had been identified.

Eventually, 18 assessment methods were identified that were appropriate for our outcomes and for which we had (or could obtain) data. Each method was rated as either a strong or weak measure of various outcomes, as illustrated in Table 3. The methods for assessing student performance include obvious choices such as monitoring of student progress, exit interviews, alumni and employer surveys, and feedback from various advisory boards. However, several measures, such as annual faculty evaluations, were included primarily for evaluating the outcomes associated with the School's operations and programs.

Most of the 18 assessment methods provide data that can be used directly in evaluating outcomes and the related objectives. However, there are potential problems that must be considered in selecting assessment methods. Issues such as "What does it really measure?," "How reliable are the data?," or "Does it depend on an unverified relationship?" may render a potentially desirable measure unusable. This is readily illustrated by the following two examples.

1) The method for achieving many of the curricular objectives is through required coursework, with a corresponding outcome of specific skills or knowledge. This outcome is most easily assessed by a review of the student's transcript prior to graduation to ensure that all required course have been passed. However, this assessment is only valid if the course content actually includes the expected skill or knowledge and the course grading ensures a satisfactory level of achievement, issues that must be evaluated independently. Alternatively, 
one could attempt to identify an assessment method that directly measures the desired skill or knowledge.

2) One of the other Schools at Georgia Tech has recently considered requiring all students to take the Fundamentals of Engineering exam as a condition of graduation. This would seem to be a useful assessment tool, since all graduates would participate and results could be compared to national norms. However, since students cannot be required to pass the exam, many of them may not take it seriously and their scores will not accurately reflect their capabilities. (When Georgia Tech previously required all engineering students to take the exam, some students simply signed their names and left.) Under such circumstances, the reliability of the data is seriously compromised. Strangely, the FE exam may serve as a better assessment measure if taken voluntarily by a subset of students than if it were required.

Given the short preparation time for our initial EC2000 evaluation, the available assessment data resulted from a series of ad-hoc efforts. Currently, we are focusing on identifying and refining a key set of assessment measures. Additionally, Georgia Tech is currently in the process of defining institutional assessment activities. The goal is to identify a set of measures that can be applied on a regular basis, allowing the analysis of historical trends and the establishment of target values for each measure in the set.

\section{Lessons Learned}

Based on our experiences in the EC2000 pilot evaluation process, we have identified several "lessons learned" which correspond either to things we feel we did well or areas in which we need improvement. While many of these will be applicable to a wide range of other programs, several reflect the large size and flexibility of our programs.

1. Minimize Number of Objectives - This was strongly recommended by our Industrial Advisory Board, based on experiences with their own assessment efforts, in order to limit the complexity of the overall process.

2. Identify a Small Set of Critical Assessment Measures - Ideally, the assessment measures should be a small set of strong indicators, easy to obtain, and consistent over time. Too much data may actually make it harder to analyze results and improve the process.

3. Clearly Define the Faculty Role - This is critical for large programs, since documentation will be prepared by a small group and the evaluator will interview only a few people. However, every faculty member needs to be knowledgeable enough to properly advise students and participate in the continuous improvement process for courses and curricula.

4. Don't Claim Credit Where It's Not Due - If a particular activity or course is claimed to contribute to the achievement of an outcome, be certain it can be documented. Adequate documentation is also needed for courses and activities in support departments.

5. Organization Matters - For a large program, the self-study, course samples, and assessment data can be overwhelming. Proper organization makes it much easier to verify that a program is actually accomplishing what it claims. For example, we 
organized course materials by category (required, individual areas of specialization, elective) rather than numerically.

6. Anticipate and React - Think like an evaluator in developing documentation and organizing supporting materials. Communicate in advance with the evaluator, react to his/her needs, and adjust during the visit. For a large program, make it easy for the evaluator to identify the subset of critical information essential to the evaluation process.

7. Balance Institutional and Program Efforts - For a large institution, use of college or institutional assessment efforts can provide consistency across programs, simplify data processing, and reduce redundant efforts.

\section{Key Unresolved Issues}

Since EC2000 is a new process, there are still several areas in which appropriate procedures or standard practices have not yet evolved. Based on our experience in this process, as well as discussions with others, the following four issues appear to be of particular concern.

1. How Should Surveys Be Used? - Surveys appear to be the best assessment tools available for many outcomes, particularly those related to the "soft" issues. However, surveys may have problems related to sample size (particularly for both very large and very small programs), reliability of self-reported data, and the time lag between the experiences of those surveyed and current curricular content and methods.

2. Setting Targets for Assessment Results - What result on an assessment measure indicates success in achieving the outcome? Are the desired results different for each institution and program, based on individual objectives, missions, and constituencies?

3. What If the Results Don't Meet Expectations? - Was the target reasonable? If so, is it sufficient to show improving trends over time and a functioning improvement process?

4. Portfolios of Student Work - While desirable for documenting student achievement, the logistical problems make it unreasonable for a large program to collect portfolios for all students. "Virtual portfolios" composed of samples of typical student work from various courses are an alternative, but still provide only a limited sample for large, flexible programs with hundreds of allowable course combinations.

\section{Conclusions}

Overall, the School of Electrical and Computer Engineering at Georgia Tech has succeeded in making the transition from the Engineering Topics model to the EC2000 model for accreditation processes. Objectives, outcomes, and assessment measures have been established. Compared to the model process from Figure 1, we have implemented all aspects except for the establishment of target values (indicators) for the assessment results.

Within our on-going efforts, we are focusing on reducing the number of objectives, identifying a smaller set of key assessment measures, and establishing historical data for the assessment 
results. Additional effort also is needed to ensure that assessment results are systematically used to improve curricula, course content, and teaching. Success will require a change in faculty mindset such that assessment and continuous improvement activities are viewed as contributing to faculty and program development, rather than an intrusion every few years to satisfy an ABET mandate.

The amount of effort required under EC2000 is significantly higher than under the Engineering Topics criteria. While partly a one-time effect, similar to the first time a program is accredited, the on-going process activity between visits constitutes a new workload. For large programs, the effort is increased due to the number of alumni, employers, etc. involved in the process.

1. Accreditation Board for Engineering and Technology, "Engineering Criteria 2000 Program Evaluator Training," September 1997.

2. Engineering Accreditation Commission, Accreditation Board for Engineering and Technology, "Engineering Criteria 2000," $2^{\text {nd }}$ ed., 1997.

JOSEPH L. A. HUGHES is Associate Professor and Vice-Chair for Computer Engineering and Program Development in the School of Electrical and Computer Engineering at Georgia Tech. He received his Ph.D. in electrical engineering from Stanford University in 1986. He is a program evaluator for both electrical engineering and computer engineering programs. His primary technical interest is integrated circuit design and testing.

WILLIAM E. SAYLE is Professor and Vice-Chair for Undergraduate Affairs in the School of Electrical and Computer Engineering at Georgia Tech. He received his Ph.D. from the University of Washington in 1970. He has recently chaired the Committee on Engineering Accreditation Activities and the Accreditation Policy Committee of the IEEE and begins service on the Engineering Accreditation Commission of ABET in July 1998. 